\title{
BORSA İSTANBUL ALT SEKTÖR ENDEKSLERİ ARASINDAKİ OYNAKLIK YAYILIMLARININ ANALIZI'1
}

Melik KAMIŞLI²

Güven SEVİ ${ }^{3}$
Received Date (Başvuru Tarihi): 26/11/2018

Accepted Date (Kabul Tarihi): 25/12/2018

Published Date (Yayın Tarihi): 04/01/2019

\section{$\ddot{O} Z$}

Yatırımcılar portföy riskini azaltmak amacıla sektörel çeşitlendirmeye gidebilmektedir. Bu durumda sağlıkl yatırım kararlarının verilebilmesi için sektörler arasında ilişkilerin doğru bir şekilde belirlenmesi gerekmektedir. Özellikle krizler sektörler arasındaki oynaklık yayılımları üzerinde doğrudan etkili olmaktadır. Bu bağlamda çalışmada krizlerin ve farklı tipteki şokların Borsa İstanbul (BIST) alt sektör endeksleri arasındaki oynaklı yayllımları üzerindeki etkilerinin belirlenmesi amaçlanmıştır. Bu amaca uygun olarak 2001 Finansal Krizi ve 2008 Küresel Krizi baz alınarak belirlenen dönemler için DCC-GARCH analizi uygulanmıştır. Sonuçlar Asya Krizi, Rusya krizi, 1999 Depremi, 2002 genel seçimi, 2003 Körfez Savaşı, Gezi Parkı olayları, 17-25 Aralık operasyonları, Merkez Bankası faiz politikaları ile sektörlere özgü olayların yayllımları etkilediğini ortaya koymuştur.

Anahtar Kelimeler: Sabit Koşullu Korelasyon Testi, Dinamik Koşullu Korelasyon Modeli, Portföy Yönetimi

JEL Kodlarl: C58, G01, G11

\section{ANALYSIS OF THE VOLATILITY SPILLOVERS AMONG BORSA ISTANBUL SUB-SECTOR INDICES}

\begin{abstract}
Investors may prefer sectoral diversification in order to reduce the portfolio risk. In this case, investors should determine the relationships between the sectors properly in order to make healthy investment decisions. Especially crises directly affect volatility spillovers between the sectors. In this context, it is aimed to determine the effects of crises and different types of shocks on volatility spillovers among Borsa Istanbul (BIST) sub-sector indices. In accordance with this purpose The DCC-GARCH analysis is applied to the series which are determined based on 2001 Financial Crisis and 2008 Global Crisis. The results indicate that Asian Crisis, Russia Crisis, 1999 Earthquake, 2002 general election, 2003 Gulf War, Gezi Park events, 17-25 December operations, Central Bank interest policies and industry-specific events also had effects on spillovers.
\end{abstract}

Keywords: Constant Conditional Correlation Test, Dynamic Conditional Correlation, Portfolio Management

JEL Codes: C58, G01, G11

\footnotetext{
$1 \mathrm{Bu}$ çalışma, Anadolu Üniversitesi Sosyal Bilimler Enstitüsü Finansman Bilim Dalı Doktora öğrencisi Melik Kamışlı tarafından Prof. Dr. Güven Sevil'in danışmanlığında tamamlanan "Finansal Krizlerde Borsa İstanbul Alt Sektörleri Arasındaki Oynaklık Yayılımı: Yön, Frekans Boyutu ve Şoklar Bağlamında Analiz” başlıklı doktora tezinden türetilmiştir.

2 Dr. Öğr. Üyesi, Bilecik Şeyh Edebali Üniversitesi, melikkamisli@ gmail.com $\quad$ https://orcid.org/0000-0001-6419-2257

3 Prof. Dr., Anadolu Üniversitesi, $\quad$ gsevil@ anadolu.edu.tr $\quad$ https://orcid.org/0000-0001-7592-3799
} 


\section{GíRiş}

Yatırımcılar portföylerini oluştururken çeşitlendirmeden maksimum düzeyde faydalanabilmek amacıyla hisse senedi piyasasında yer alan alt sektörleri baz alarak varlık dağıtımı kararlarını alabilirler. Ancak farklı türdeki krizlere bağlı olarak değişen oynaklık yayılımları sonucunda, yatırımcıların portföylerini çeşitlendirerek düşük risk ile yüksek getiri elde etme firsatları azalmakta, dolayısıyla analizlerin daha kapsamlı bir şekilde yapılması gerekliliği ortaya çıkmaktadır. Bu nedenle finansal değişkenler arasındaki oynaklık ilişkisinin yapısının ve farklı türdeki şoklar karşısında ne şekilde değişim gösterdiğinin bilinmesi, yatırım kararları ve risk yönetim stratejilerinin belirlenmesi açısından oldukça önemlidir.

Özellikle kriz dönemlerinde, finansal varlıklar arasındaki oynaklık yayılımların belirli yapıdaki şoklara karşı nasıl değişim gösterdiğinin belirlenmesi için zamana bağlı korelasyonların incelenmesi, ilişkilerin daha doğru bir şekilde ortaya konmasına olanak tanımaktadır. Engle (2002) tarafından geliştirilen ve iki değişken arasındaki korelasyonu hesaplarken değişkenlerin tarihi oynaklıklarına ilişkin değerli bilgileri de içeren dinamik koşullu korelasyon (DCC) modeli bu amaçla kullanılabilmektedir (Hinojales ve Park, 2011: $181)$.

Ülkemizde 2001 y1lında yaşanan Finansal Kriz ve 2008 y1lında yaşanan Küresel Kriz farklı dinamiklere sahiptir ve finansal piyasaları olumsuz yönde etkilemiştir. Bununla birlikte krizlerin ulusal veya uluslararası boyutta olması, oynaklık yayılımının yapısını ve etkisini değiştirmektedir. Bu bağlamda çalışmanın temel amacı; farklı türde gerçekleşen krizlere bağlı olarak, DCC-GARCH(1,1) modeli ile Borsa İstanbul (BİST) alt sektör endeks getirilerinin kendi sektör grupları içinde değişen oynaklık yayılımlarının hangi olaylara bağlı olarak zamanla değişim gösterdiğinin belirlenmesidir.

\section{DİNAMIK KOŞULLU KORELASYON ANALIZİ İLE YAPILAN}

\section{ÇALIŞMALAR}

Finansal varlıklar arasındaki oynaklık ilişkileri farklı şoklar karşısında sabit ya da dinamik bir yapı gösterebileceği gibi, yayılımların yapısı şoklara bağlı olarak da değişebilmektedir. Literatürde finansal varlıklar arasındaki oynaklık ilişkilerini çoklu genelleştirilmiş otoregresif. koşullu değişen varyans (MGARCH) modelleri ile inceleyen birçok çalışma bulunmaktadır.

Kearney ve Poti (2006), Xiao ve Dhesi (2010) ve Durai ve Bhaduri (2011) DCC analizi ile hisse senedi piyasaları oynaklık yayılımlarını ve korelasyon yapılarını incelemişlerdir. 
Kearney ve Poti (2006) Avrupa'nın 5 gelişmiş hisse senedi endeksi arasındaki korelasyon yapılarını ortaya koymak amacıyla DCC ve asimetrik DCC modellerini kullanmış ve endeksler arasındaki koşullu korelasyonun asimetrik bir yapıda olduğunu tespit etmiştir. Xiao ve Dhesi (2010) Amerika ile Avrupa hisse senedi piyasaları arasındaki oynaklık yayılımlarını ve koşullu korelasyon yapılarını BEKK ve DCC modelleri ile analiz etmiş ve Amerika'dan Avrupa hisse senedi piyasalarına oynaklık yayılımları olduğunu ve korelasyonların zamanla değişen yapıda olduğunu ortaya koymuştur. Durai ve Bhaduri (2011) ise DCC modelini kullanarak Hindistan ile gelişmiş ve gelişmekte olan ülkeler arasındaki korelasyon yapısını incelemiş ve Hindistan ile belirlenmiş ülkeler arasındaki korelasyonların düşük olduğunu belirleyerek, yatırımcıların çeşitlendirme için Hindistan borsasını kullanabileceklerini belirtmiştir. Horng ve Chyan (2009), Sadorsky (2012) ve Chang vd. (2013) ise DCC modellerini petrol fiyatları ile hisse senedi piyasaları arasındaki oynaklık yayılımlarını belirlemek amacıyla kullanmışlardır. Horng ve Chyan (2009) Tayland ve Singapur hisse senedi piyasası getirileri ve söz konusu piyasalar ile petrol fiyatları arasındaki oynaklık ilişkilerini analiz ederek, hisse senedi piyasaları arasında pozitif ilişkiler olduğu, her iki piyasanın da petrol fiyatlarındaki oynaklıklardan etkilendiği sonucuna ulaşmışlardır. Sadorsky (2012) temiz enerji şirketleri, teknoloji şirketleri ve petrol fiyatları arasındaki oynaklık yayılımlarını, aralarında sabit koşullu korelasyon (CCC) ve DCC'nin de bulunduğu MGARCH modelleri ile test etmişlerdir. Çalışma sonucunda en iyi modelin DCC olduğu belirlenmiş ve temiz enerji şirketleri ile teknoloji şirketlerinin hisse senetleri arasında yüksek korelasyon ilişkisi bulunmuştur. Chang vd. (2013) ise ham petrol fiyatları ile hisse senedi piyasaları arasındaki oynaklık yayılımlarını farklı ekonometrik yöntemler ile incelemişlerdir. Çalışmada değişkenler arasında oynaklık yayılımları tespit edilmiş ve DCC modeli sonuçları değişkenler arasındaki korelasyon ilişkilerinin dinamik bir yapıda olduğunu ortaya koymuştur.

Lien ve Yang (2009), Savva vd. (2009), Wang ve Moore (2012), Caporin (2013) ve Yilmaz vd. (2015) çalışmalarında farklı finansal piyasalar ve endeksler arasındaki oynaklık yayılım ilişkilerini belirlemek amacıyla koşullu korelasyon modellerinden yararlanmışlardır. Lien ve Yang (2009) uluslararası bakır future piyasaları arasındaki getiri ve oynaklık yayılımlarını belirlemek amacıyla DCC-GARCH modelinden yararlanmışlar ve Londra ve New York borsaları arasında karşılıklı getiri ve oynaklık yayılımları olduğunu belirlemişlerdir. Savva vd. (2009) ise Euro'ya geçişin Amerika ile gelişmiş Avrupa piyasaları arasındaki oynaklık yayılımları ve korelasyonlar üzerindeki etkilerini tespit etmeyi amaçlamışlardır. Çalışma ile Euro'ya geçişin ardından korelasyonların arttığını ve oynaklık yayılımlarının 
bulunduğunu göstermişlerdir. Wang ve Moore (2012) Küresel kriz döneminde gelişmiş ve gelişmekte olan ülke kredi temerrüt swapı (CDS) spreadlerinin Amerika CDS spreadi ile olan entegrasyonunu incelemişlerdir. Çalışmada Lehman Brothers'ın iflasının özellikle gelişmiş ülke CDS spreadleri ile Amerika CDS spreadi arasındaki entegrasyonu arttırdığı belirlenmiştir. Çalışma ile ayrıca yüksek korelasyon ilişkilerinin nedeninin Amerika'da düşen faiz oranları olduğu tespit edilmiştir. Caporin (2013) oynaklık endeksi (VIX) ve CDS endekslerinin hedge stratejisi oluşturulmasında kullanımından hareketle, sektörel endeksler ile söz konusu endeksler arasındaki ilişkileri analiz etmişlerdir. Çok sayıda ekonometrik modelin kullanıldığı çalışma ile hedge stratejilerinde koşullu korelasyon dinamiklerinin kullanımının etkinliği arttırdığını vurgulamışlardır. Yilmaz vd. (2015) ise çalışmalarında Dow Jones İslamik Piyasa sektör endeksleri arasındaki ilişkileri incelemişler ve sektörler arasındaki korelasyonun arttığını, bu nedenle sektörel çeşitlendirme olanaklarının azaldığını ortaya koymuşlardır.

Literatürde oynaklık yayılımlarını krizler bağlamında, farklı piyasalar ve endeksler için DCC modelleri ile inceleyen birçok çalışma bulunmaktadır. Bu çalışmalardan bazıları oynaklık yayılımlarını analiz ederken belirli bölge veya ülke gruplarını baz almaktadır. Chiang vd. (2007), Yiu vd. (2010) ve Thao vd. (2013) krizlerin Asya ülkeleri üzerindeki etkilerini araştırmışlardır. Chiang vd. (2007) Asya Krizi’nin Asya ülkelerine bulaşıcılık etkilerini sınamışlardır. Ampirik sonuçlar, krizin erken dönemlerinde bir bulaşıcılık etkisinin olduğunu, ilerleyen dönemde ise yatırımcılarda sürü psikolojisi davranışının oluştuğunu göstermiştir. Yiu vd. (2010) Küresel Kriz’in Asya hisse senedi piyasalarına bulaşıcılık etkilerini incelemişler ve kriz döneminde bulaşıcılığın arttığı, iyi ve kötü haberlerin etkilerinde ise asimetri olmadığı sonucuna ulaşmışlardır. Thao vd. (2013) Küresel Kriz’in Doğu Asya ülkelerine yayılımlarını irdelemişlerdir. Çalışmada CCC ve DCC modelleri kullanılmış ve krizin ülkelere farklı dönemlerde yayılım gösterdiği sonucuna ulaşılmıştır. Ampirik sonuçlar incelendiğinde, Asya ülkelerinin kendileri arasındaki korelasyonun, Amerika ile olan korelasyondan yüksek olduğu, dolayısıyla krizin birbirine yakın ülkeler arasındaki korelasyonu arttırdığı tespit edilmiştir. Küresel Kriz'in ardından, krizin oynaklık yayılımları üzerindeki etkilerini DCC-GARCH modeli ile analiz eden çalışmalar yapılmıştır (Naoui vd., 2010; Syllignakis ve Kouretas, 2011; Min ve Hwang, 2012; Guesmi vd., 2013; Hwang vd., 2013 ve Dimitriou vd., 2013). Naoui vd. (2010) Amerika ve gelişmekte olan ülke hisse senedi piyasaları arasındaki korelasyonları ve 2008 Küresel Krizi'nin bulaşıcılık etkilerini analiz etmişlerdir. Ampirik sonuçlar Çin dişında diğer ülkeler ile Amerika arasında yüksek koşullu korelasyonların olduğunu ve krizin, Çin, Endonezya ve Tayvan dışındaki ülkelere bulaşıcılık etkileri gösterdiğini ortaya koymuştur. 
Syllignakis ve Kouretas (2011)'a ait çalışmada ise 2008 Küresel Krizi nedeniyle Amerika, Almanya ve Rusya'dan, merkez ve doğu Avrupa'daki gelişmekte olan ülke piyasalarına bulaşıcılık etkileri irdelenmiş ve kriz döneminde koşullu korelasyonların arttığını, dolayısıyla bulaşıcılık etkilerinin olduğunu göstermiştir. Min ve Hwang (2012) Amerika ve OECD ülkeleri hisse senedi piyasaları arasındaki dinamik koşullu korelasyonları analiz ederek 2008 Küresel Krizi’nin OECD ülkeleri üzerindeki bulaşıcılık ve sürü psikolojisi etkilerini araştırmışlardır. Analiz sonuçları, İngiltere, Avustralya ve İsviçre'de krizin ilk aşamasında bulaşıcılık, ikinci aşamasında ise sürü psikolojisi davranışı olduğunu göstermiştir. Guesmi vd. (2013) OECD ile Amerika hisse senedi piyasalarının birlikte hareketlerini ve Küresel Kriz'in OECD ülkelerine bulaşıcılık etkilerini sınamışlar ve bulaşıcılık etkileri tespit etmişlerdir. Hwang vd. (2013) gelişmekte olan ülke piyasa getirilerinin kendi aralarındaki ve Amerika ile olan ilişkilerini irdelemişlerdir. Çalışma ile tüm ülkeler arasındaki korelasyonlarda, bulaşıcılığa işaret eden artışlar olduğu sonucuna ulaşılmıştır. Dimitriou vd. (2013) ise 2008 Küresel Krizi’nin gelişmekte olan ülke hisse senedi piyasalarına etkilerini belirlenen dönemler itibariyle incelemiş ve Lehman Brothers'ın iflasının ardından, piyasalar arasında yeniden ilişkilerin başladığını tespit etmişlerdir.

\section{METODOLOJI VE DATA}

Portöy ve risk yönetimi açısından portföye dahil edilecek finansal varlıklar arasındaki oynaklık yayılımına neden olan olayların belirlenmesi büyük önem taşımaktadır. DCC modeli ise iki değişken arasındaki koşullu korelasyonun pozitif, negatif veya sıfır olabildiği dönemlerin belirlenmesine imkân vermektedir (Hinojales ve Park, 2011: 181). Bu nedenle çalışmada dinamik koşullu korelasyon analizi uygulanmıştır. DCC analizine geçilmeden önce söz konusu endeks getirileri arasındaki korelasyonların sabit ya da dinamik bir yapıda olduğunun belirlenebilmesi için ise Engle ve Shepard (2001) tarafından geliştirilen sabit koşullu korelasyon testi uygulanmıştır. İlerleyen adımda aralarında sabit koşullu korelasyon bulunan endeks getirileri dışında kalan diğer tüm endeks getirileri arasındaki oynaklık yayılımları, DCC-GARCH $(1,1)$ modeli ile analiz edilmiştir.

Engle (2002) tarafından geliştirilen DCC modeli ile değişkenler arasında zamana göre değişen dinamik koşullu korelasyon katsayılarına ulaşılmaktadır. DCC modelinde, koşullu varyans matrisi hiyerarşik bir yolla belirlenir. İlk olarak, geleneksel GARCH modelinde olduğu gibi her koşullu varyans için bir model seçilir. Ardından, koşullu varyanslara bağlı olarak koşullu korelasyon matrisi modellenir. Koşullu varyans matrisinde olduğu gibi koşullu 
korelasyon matrisi de her zaman noktası için pozitif tanımlı olmalıdır. DCC modelinde koşullu ortalama eşitliği;

$$
y_{t}=E\left(y_{t} / I_{t}\right)+r_{t}
$$

burada $I_{t-1}, \mathrm{t}-1$ 'inci gözlemdeki bilgi setidir.

Her tek değişkenli hata süreci $r_{i, t}=h_{i, t}^{1 / 2} \varepsilon_{i, t}$ spesifikasyonuna ve tek değişkenli $\operatorname{GARCH}(1,1)$ sürecini izleyen $E=\left(r_{i, t}^{2} / I_{t-1}\right)=h_{i, t}$ koşullu varyansına sahiptir. Burada;

$$
h_{i, t}=\omega_{i 0}+\alpha_{i 1} r_{i, t-1}^{2}+\beta_{i 1} h_{i, t-1}
$$

Koşullu korelasyonlar aşağıdaki eşitlikte verilen $\operatorname{GARCH}(1,1)$ modelinden yola çıkılarak zamanla değişen bir hale getirilmektedir.

$$
q_{i j, t}=\bar{p}_{i j}(1-\alpha-\beta)+\alpha \varepsilon_{i, t-1}+\beta q_{i j, t-1}
$$

burada $q_{i j, t}, \varepsilon_{t}$ 'nin zamanla değişen kovaryansı, $\bar{p}_{i j}$ ise $\alpha$ ve $\beta$ parametrelerinin negatif olmadığı durumlarda $\varepsilon_{t}$ 'nin koşulsuz varyansıdır.

Çalışmada; 02.01.1997 - 24.03.2015 tarihleri arasında, BIST Sınai (XUSIN), Hizmetler (XUHIZ) ve Mali (XUMAL) sektör endeksleri içerisinde yer alan Gıda, İçecek (XGIDA), Orman, Kağıt, Basım (XKAGT), Kimya, Petrol, Plastik (XKMYA), Metal Ana (XMANA), Metal Eşya, Makina (XMESY), Taş, Toprak (XTAST), Tekstil, Deri (XTEKS), Elektrik (XELKT), İletişim (XILTM), Spor (XSPOR), Ticaret (XTCRT), Turizm (XTRZM), Ulaştırma (XULAS), Banka (XBANK), Finansal Kiralama, Faktoring (XFINK), Gayrimenkul Yatırım Ortaklığı (XGMYO), Holding ve Yatırım (XHOLD) ve Sigorta (XSGRT) alt sektör endekslerine ait 4.516 günlük kapanış değerleri üzerinden hesaplanan getiriler kullanılmıştır.

Çalışmada ele alınan veri seti, endekslerin hesaplanmaya başlandığı 02.01.1997 24.03.2015 yılları ile sınırlandırılmıştır. Dönemlerin belirlenmesinde 2001 Finansal Krizi için devlet yönetiminde siyasi krizin yaşandığı 19.02.2001 tarihi ve 2008 Küresel Kriz’in başlangıcı olarak kabul edilen, Lehman Brothers'ın iflas ettiği 15.09.2008 tarihi esas alınmıştır. Krizler baz alınarak belirlenen dönemler aşağıdaki şekildedir;

$$
\begin{aligned}
& \text { 1. Dönem: } 02.01 .1997-19.02 .2001 \text { (1. Dönem) } \\
& \text { 2. Dönem: } 20.02 .2001-15.09 .2008 \text { (2. Dönem) } \\
& \text { 3. Dönem: } 16.09 .2008-24.03 .2015 \text { (3. Dönem) }
\end{aligned}
$$

“İletişim", "Spor” ve "Gayrimenkul Y. O.” alt endeksleri ise hesaplanmaya başlandıkları tarih itibariyle, çalışmada belirlenen dönemlerde yer almaktadır. Söz konusu alt 
sektör endekslerine ait kapanış değerleri, Thomson \& Reuters Datastream veri tabanı üyeliği ile elde edilmiştir. Uygulanan testler sonucunda oynaklık ilişkilerin değişimine neden olan olayların belirlenmesinde "Reuters News" veri tabanı taranmıştır.

\section{ANALİZ SONUÇLARI}

Çalışmada analiz edilen alt sektör endeks getirilerinin; içerisinde yer aldıkları sektörler ve belirlenen dönemler itibariyle durağanlığını sınayan $\mathrm{Ng}$-Perrron birim kök testi sonuçları Ek-1'te verilmiştir. Hem sabitli hem de sabitli ve trendli model için Ng-Perrron birim kök testi sonuçlarına göre, ele alınan tüm alt sektör endeks getirileri belirlenen dönemler itibariyle durağandır. İlerleyen adımda ise alt sektör endeks getirileri arasındaki ilişkinin sabit ya da dinamik özellik gösterdiğinin belirlenebilmesi amacıyla dönemler itibariyle sabit koşullu korelasyon testi yapılmış ve sonuçlar Ek-2'de özetlenmiştir.

Sabit koşullu korelasyon test sonuçlarına göre 2001 Finansal Krizi öncesi ele alınan dönemde sadece “Gıda, İçecek” ile “Orman, Kağıt, Basım”, "Kimya, Petrol, Plastik”, "Metal Ana", "Metal Eşya, Makine"; "Ticaret” ile "Ulaştırma" alt sektör endeks getirileri arasında sabit korelasyon, diğerleri arasındaki dinamik korelasyon bulunmaktadır. Ancak 2001 Finansal Krizi ve 2008 Küresel Krizi nedeniyle bir çok alt sektör endeks getirisi arasındaki korelasyon yapısı değiş̧miştir.

2001 Finansal Krizi’nin ardından “Gıda, İçecek”-“Kimya, Petrol, Plastik” ve “Ticaret”"Ulaştırma" alt sektör endeks getirileri arasındaki sabit korelasyon dinamik bir yapıya;"Orman, Kağıt, Basım”-“Taş, Toprak"; “Ticaret”-“Turizm” ve "Holding ve Yatırım”-“ Sigorta” alt sektör endeks getirileri arasındaki dinamik korelasyonlar ise sabit korelasyona dönmüştür.

2008 Küresel Krizi’nin korelasyon yapıları üzerindeki etkileri ise daha fazla olmuştur. Söz konusu krizin ardından “Gıda, İçecek”-“Kimya, Petrol, Plastik”; “Orman, Kağıt, Basım”"Kimya, Petrol, Plastik"; “Orman, Kağıt, Basım"- "Metal Ana"; “Orman, Kağıt, Basım""Metal Eşya, Makina"; "Kimya, Petrol, Plastik"-“Taş, Toprak"; "Banka"- "Holding ve Yatırım" ve "Finansal Kiralama, Faktoring"- "Holding ve Yatırım" alt sektör endeks getirileri arasındaki dinamik korelasyon yapısı sabite, "Gıda, İçecek”-"Metal Ana”; "Orman, Kağıt, Basım”-“Taş, Toprak”; “Ticaret”-“Turizm”; “Elektrik”-“Turizm” ve "Holding ve Yatırım”"Sigorta" arasındaki sabit korelasyonlar dinamik bir yapıya dönmüştür. Çalışmanın son aşamasında, belirlenen sabit korelasyonlar dışında kalan tüm alt sektör getirileri arasındaki oynaklık yayılım yapısı DCC-GARCH(1,1) ile analiz edilmiş ve model sonuçları EK-3'te 
verilmiştir. Aşağıda yer alan şekillerde ise dönemler itibariyle alt sektör getirileri arasındaki koşullu korelasyon grafikleri gösterilmiştir.
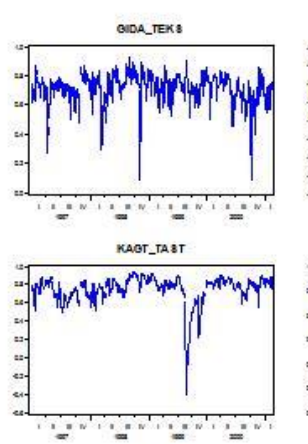

KMYYA_taBt

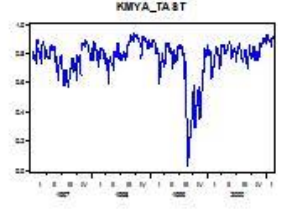

mava_rexs

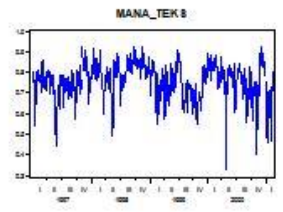

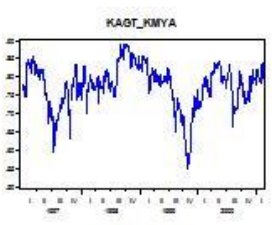

KAGT_REKs

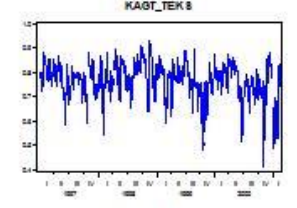

KMYA_tEKS
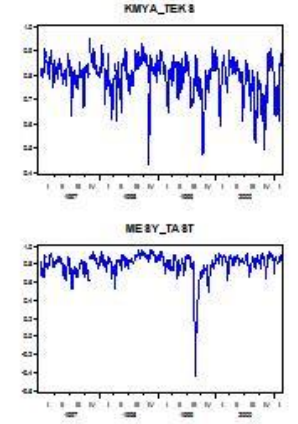

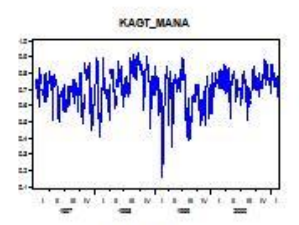

кurramana

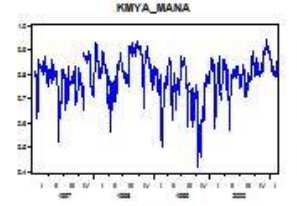

Marajuesr

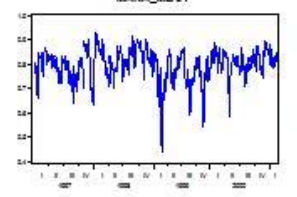

MESY_TEKs

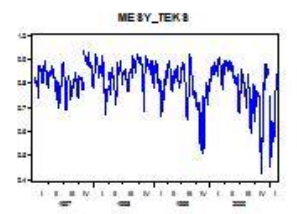

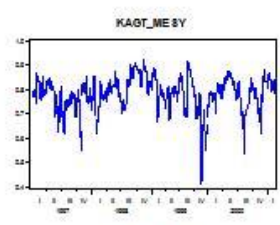

KurAMEar

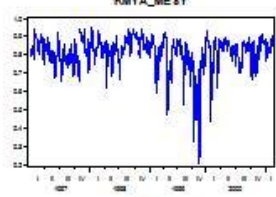

mava_tast

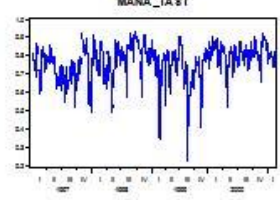

TAKs_teKs

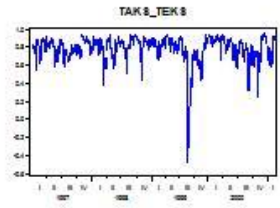

Şekil 1: 1. Dönemde Sınai Alt Sektör Endeks Getirileri Arasındaki Koşullu Korelasyonlar

Şekil 1'den görülebileceği gibi 1997 yılının 2. çeyreğinde Asya Krizi'nin etkisiyle; “Tekstil, Deri” alt sektör endeks getirisinin "Gıda, İçecek”, “Orman, Kağıt, Basım”, “Kimya, Petrol, Plastik" ve "Metal Ana" alt sektör endeks getirileri ile ve "Kimya, Petrol, Plastik" alt sektör endeks getirisinin “Orman, Kağıt, Basım” ve” Metal Ana” alt sektör endeks getirileri arasındaki oynaklık ilişkisi değişmiştir. Rusya ekonomisindeki sıkıntılar da özellikle "Orman, Kağıt, Basım”, "Kimya, Petrol, Plastik" ve "Metal Ana" alt sektör endeks getirilenin diğer alt sektör endeks getirileri ile olan oynaklık ilişkilerini değiştirmiştir. 17 Ağustos 1999 tarihinde yaşanan Marmara depremi nedeniyle "Taş, Toprak” ile "Orman, Kağıt, Basım”, "Kimya, Petrol, Plastik", "Metal Ana” ve "Metal Eşya, Makine” arasındaki oynaklık ilişkilerinde ve "Kimya, Petrol, Plastik" ve "Tekstil, Deri” alt sektör endeks getirileri arasındaki oynaklık ilişkilerinde değişim yaşanmıştır. 12 Kasım Düzce depremi ise "Metal Ana" ile "Kimya, Petrol, Plastik", "Metal Eşya, Makine" ve "Taş, Toprak" alt sektör endeks getirileri ve "Metal Eşya, Makine" ile "Kimya, Petrol, Plastik", "Orman, Kağıt, Basım” ve "Tekstil, Deri” alt sektör endeks getirileri arasındaki oynaklık ilişkileri üzerinde etkili olmuştur. 

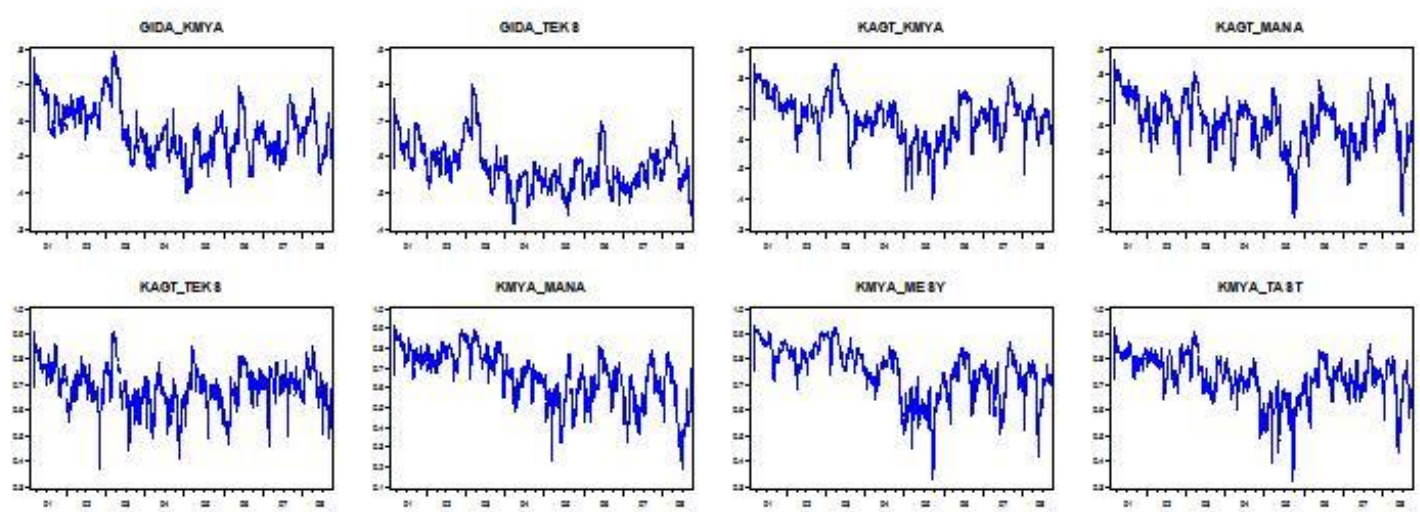

Kura_mana

KMYA_MESY
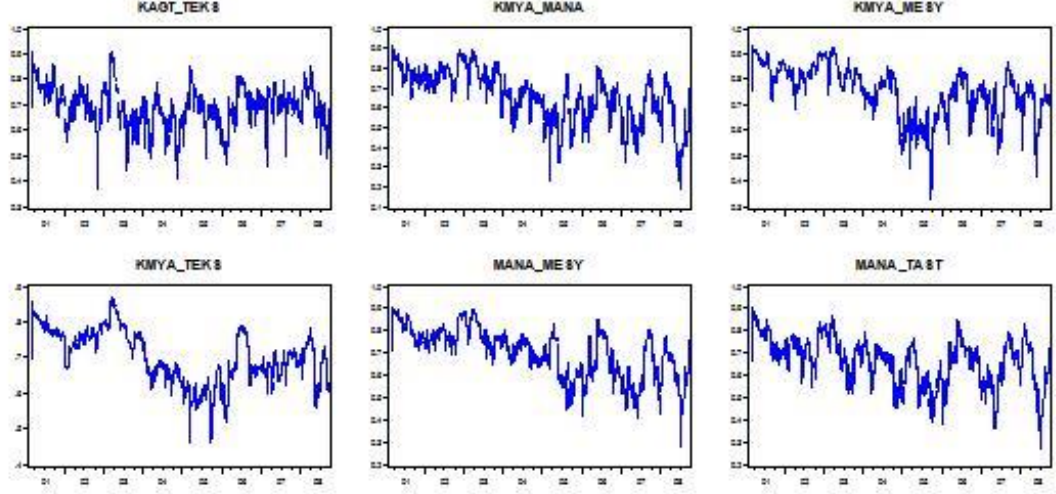

KMYA_TA8T

MaNa.MEsY

Mava_ta BT
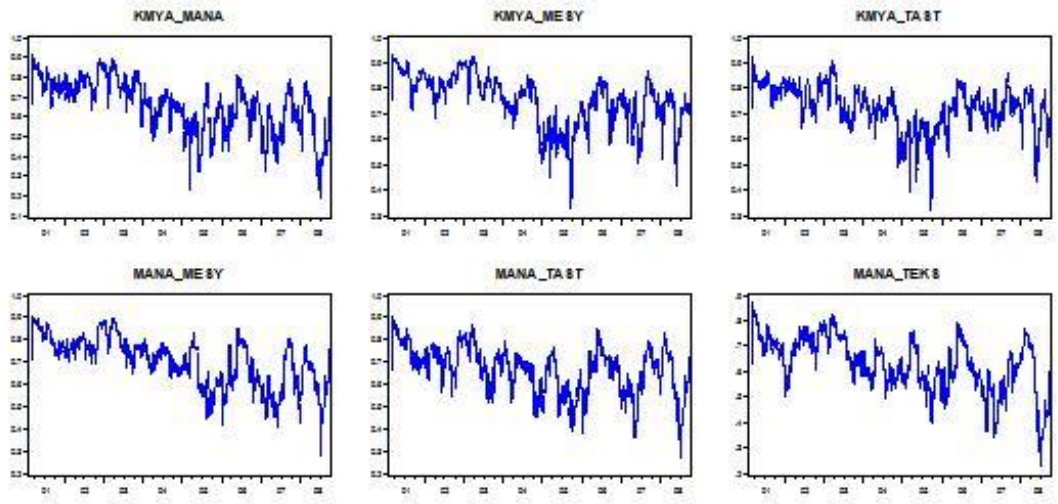

MEBY_TABT
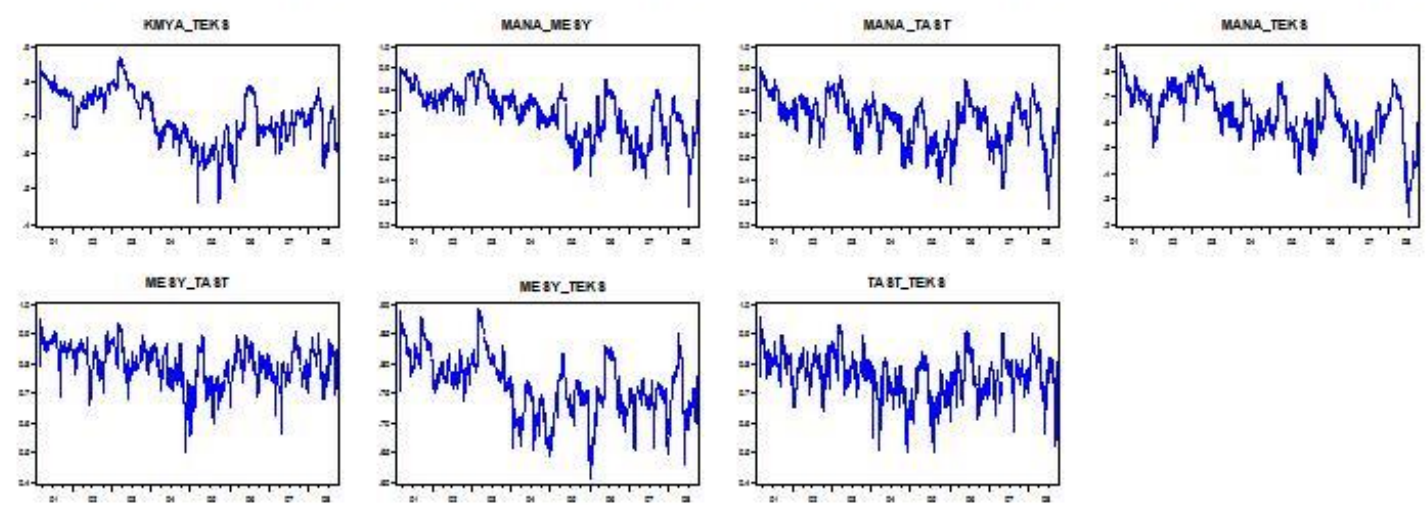

Şekil 2: 2. Dönemde Sınai Alt Sektör Endeks Getirileri Arasındaki Koşullu Korelasyonlar

Şekil 2 incelendiğinde söz konusu dönemde gerçekleşen 2002 genel seçimlerinin "Orman, Kağıt, Basım" alt sektör endeks getirisi ile "Kimya, Petrol, Plastik", "Metal Ana" ve “Tekstil, Deri” alt sektör endeks getirileri arasındaki oynaklık ilişkisi üzerindeki etkisi görülmektedir. Ancak 2003 Körfez Savaşı genel olarak oynaklık ilişkilerin değişmesine neden olmuş ve özellikle "Kimya, Petrol, Plastik" ve "Tekstil, Deri” alt sektör endeks getirilerinin diğer alt sektör endeks getirileri ile olan oynaklık ilişkisi değişmiştir. Bununla birlikte analiz döneminin 2. yarısında, ilerleyen süreçte küresel krize dönüşen Amerika' da yaşanan ekonomik gelişmelerin, tüm alt sektör endeks getirileri arasındaki oynaklık ilişkileri üzerinde etkili olduğu görülmektedir. 

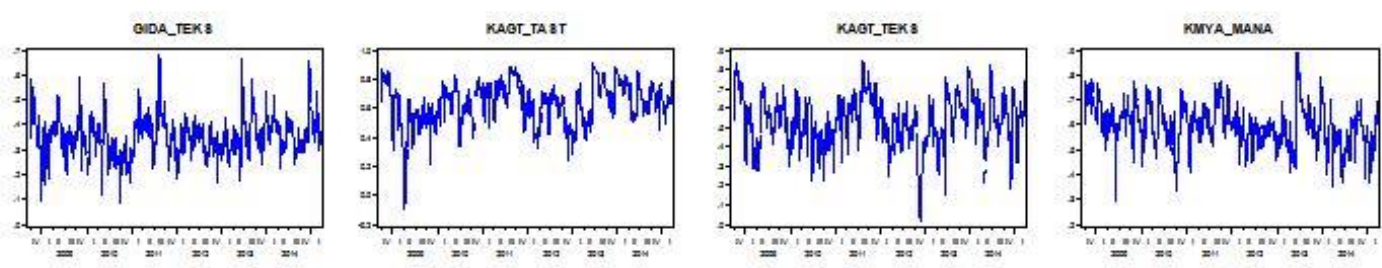

KUYALMEgr
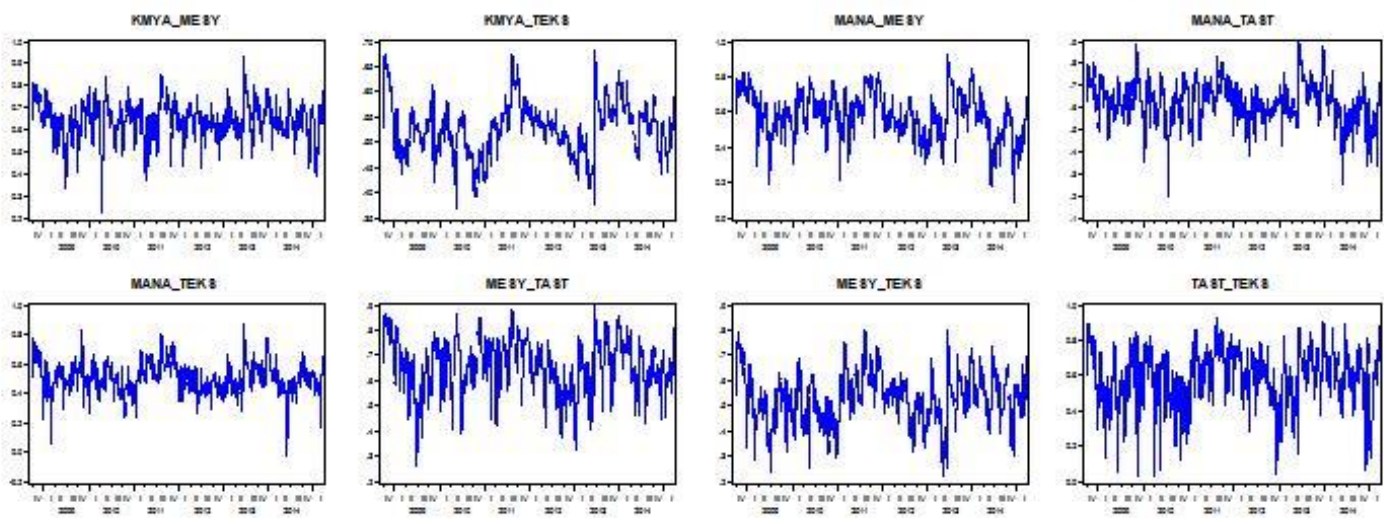

Şekil 3: 3. Dönemde Sınai Alt Sektör Endeks Getirileri Arasındaki Koşullu Korelasyonlar

Şekilden 3'ten görülebileceği gibi 2008 Küresel Krizi'nin ardından 3. dönemde sınai alt sektör endeks getirileri arasındaki korelasyonlar genel olarak artış göstermiştir. Ayrıca bu dönemde oynaklık ilişkilerinde sık ve kısa süreli değişimler yaşanmış ve değişimlerin kaynağ sektörel gelişmelerden çok ülkede yaşanan politik ve ekonomik gelişmeler olmuştur. Tüm alt sektör endeks getirileri arasındaki ortak oynaklık değişimleri Merkez Bankası'nın faiz oranlarında yaptığı değişiklikler, 2013 yılında yaşanan Gezi Parkı olayları ve 17-25 Aralık operasyonlarından kaynaklanmıştır.
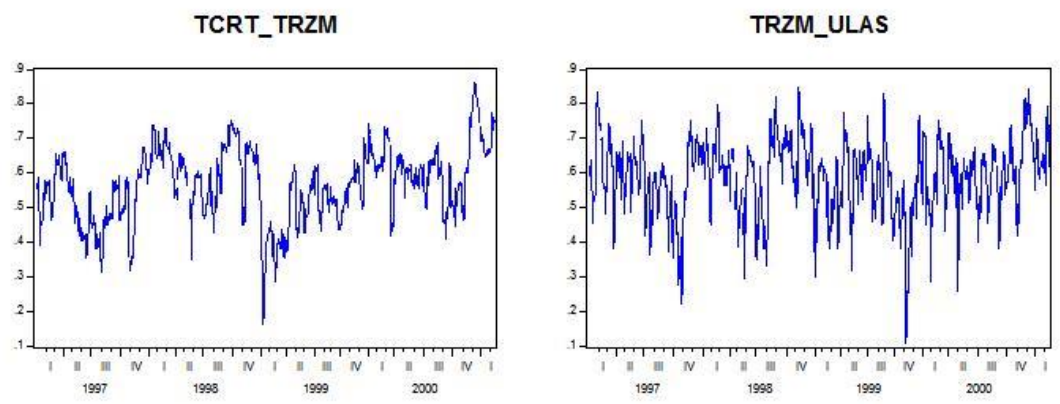

Şekil 4: 1. Dönemde Hizmetler Alt Sektör Endeks Getirileri Arasındaki Koşullu Korelasyonlar

İlk analiz döneminde hizmetler alt sektör endeks getirileri arasındaki korelasyon ilişkilerini değiştiren önemli olaylar, Rusya Krizi ve 1999 yılında yaşanan depremlerdir. Rusya Krizi’ni etkileri özellikle "Ticaret" ve "Turizm”, depremlerin etkileri ise "Turizm” alt sektör 
endeks getirisinin hem "Ticaret" hem de "Ulaştırma" alt sektör endeks getirileri ile arasındaki oynaklık ilişkileri üzerinde görülmektedir.

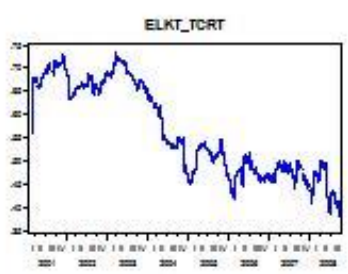

IIMLULA

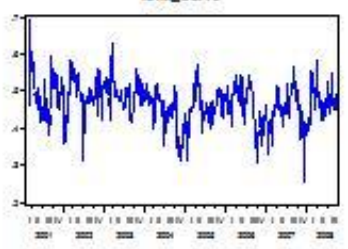

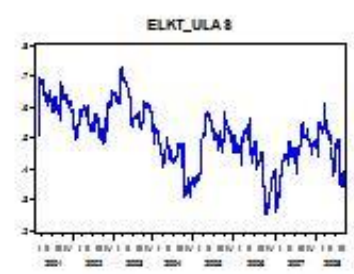

TCRT_ULA

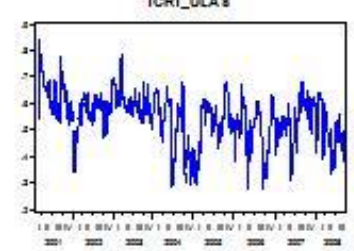

HTM_TCRT

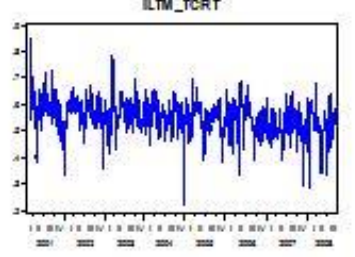

TRZMLULA 8

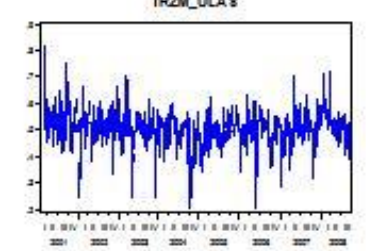

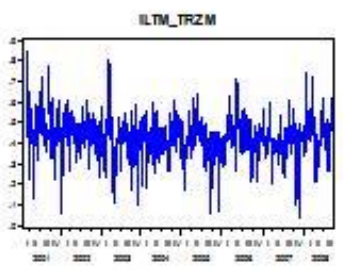

Şekil 5: 2. Dönemde Hizmetler Alt Sektör Endeks Getirileri Arasındaki Koşullu Korelasyonlar

Şekil 5'ten görülebileceği gibi 2001 Finansal Krizi nedeniyle genel olarak hizmetler alt sektör endeks getirileri arasındaki oynaklık ilişskileri oldukça değişken bir yapıya bürünmüştür. Bununla birlikte, özellikle 2003 Körfez Savaşı'nın ardından "Elektrik” alt sektör endeks getirisinin "Ticaret" ve "Ulaştırma" alt sektör endeks getirileri ile arasındaki korelasyonlar düşmüştür.

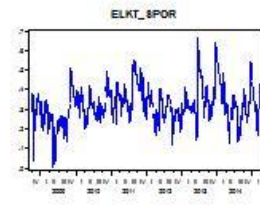

IIMUICRT

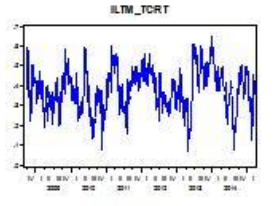

apor_ULAB

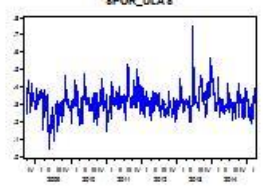

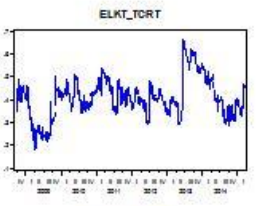

nтм_IRZM

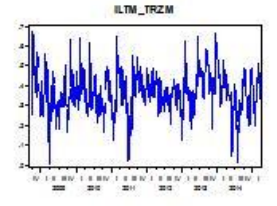

TCRT_IRZM

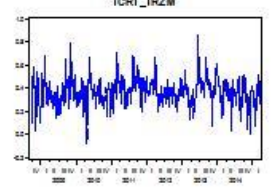

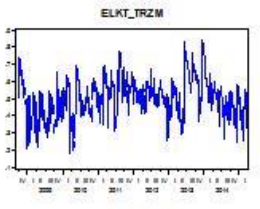

atm_unas

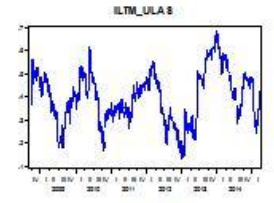

TCRT_ULAS

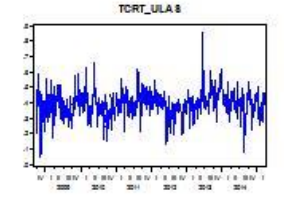

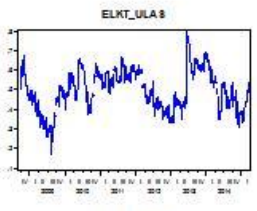

spor.mRZ

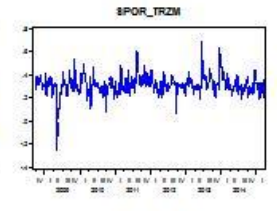

TRZU_ULA:

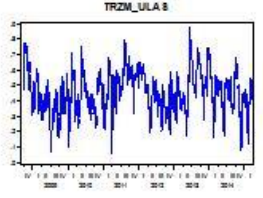

Şekil 6: 3. Dönemde Hizmetler Alt Sektör Endeks Getirileri Arasındaki Koşullu Korelasyonlar

3. dönem hizmetler alt sektör endeks getirileri arasındaki oynaklık ilişkileri, sınai alt sektör endeks getirileri arasında olduğu gibi 2008 Küresel Krizi, Gezi Parkı olayları ve 17-25 Aralık operasyonlarından etkilenmiştir. Diğer yandan 2009 yılında ekonomide yaşanan daralma 
genel olarak hizmetler alt sektör getirileri arasındaki korelasyonların azalmasına neden olmuş ve yılın son döneminde domuz gribinin ardından alt sektör endeks getirileri arasındaki oynaklık ilişkileri azalan talep nedeniyle değişmiştir.
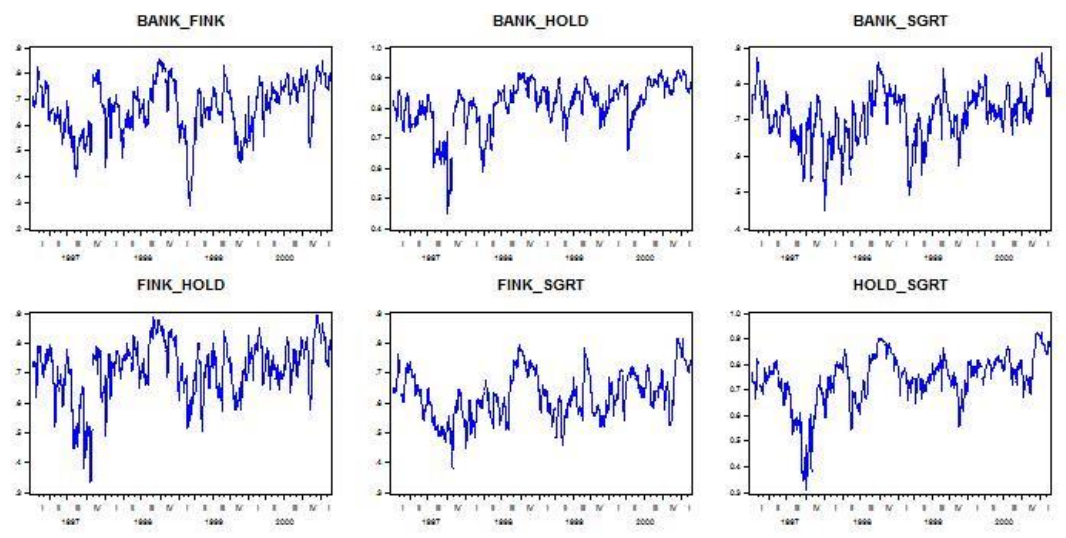

Şekil 7: 1. Dönemde Mali Alt Sektör Endeks Getirileri Arasındaki Koşullu Korelasyonlar

Şekil 7 incelendiğinde Asya ve Rusya krizlerinin etkileri tüm mali alt sektör endeks getirileri arasındaki oynaklık yayılımlarında görülmektedir. Bununla birlikte, 1999 yılında yaşanan ekonomik daralma özellikle "Banka" ile "Finansal Kiralama, Faktoring" ve "Holding ve Yatırım” alt sektör endeks getirileri arasındaki oynaklık ilişkilerini değiştirmiştir.

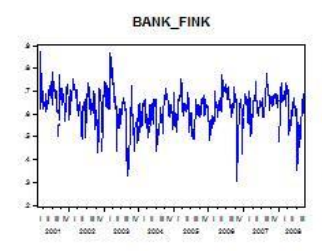

BANK_SGRT

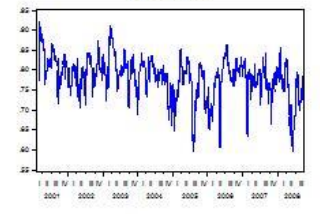

FINK_SGRT

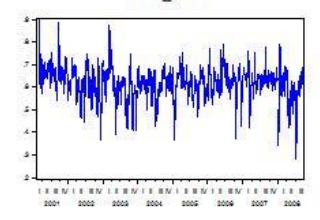

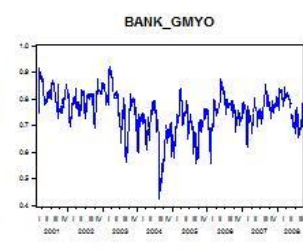

FINK_GMYO

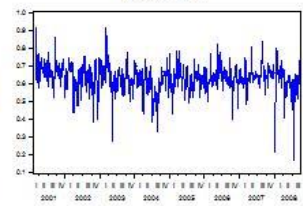

GMYO_HOLD

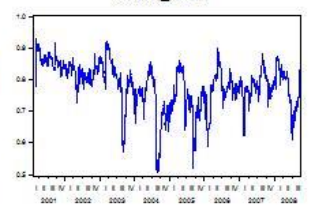

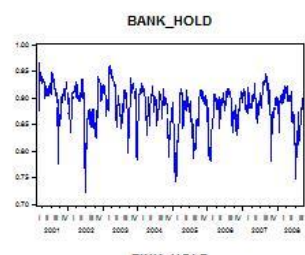

FINK_HOLD

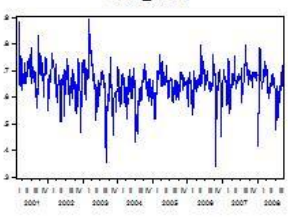

GMYO_SGRT

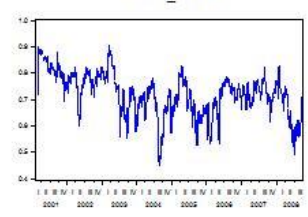

Şekil 8: 2. Dönemde Mali Alt Sektör Endeks Getirileri Arasındaki Koşullu Korelasyonlar

Şekil 8'den görülebileceği gibi mali alt sektör endeks getirileri arasındaki oynaklık ilişkileri 2001 Finansal Krizi nedeniyle genel olarak değişken bir hale gelmiştir. Diğer alt sektör endeks getirileri arasındaki oynaklık yayılımlarını etkileyen 2003 Körfez Krizi'nin etkileri, benzer şekilde mali alt sektör endeks getirileri arasındaki oynaklık yayılımlarında da 
gözlemlenmiştir. Bununla birlikte, özellikle yabancı sermaye girişlerindeki artışlarla birlikte 2004 y1lından sonra "Banka", "Gayrimenkul Y. O." ve "Sigorta" alt sektör endeks getirileri arasındaki oynaklık ilişkilerinde değişim yaşanmıştır.

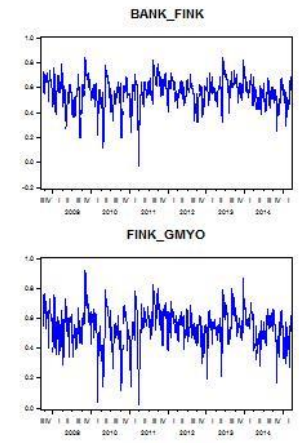

GMYO_SGRT

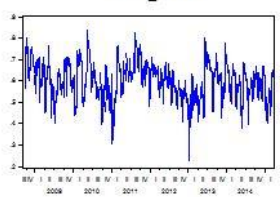

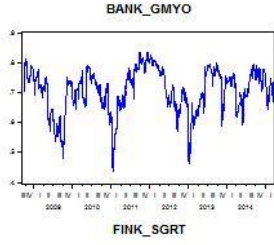

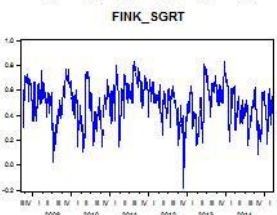

HOLD_SGRT

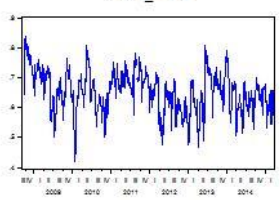

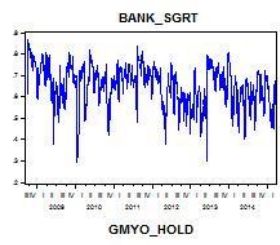

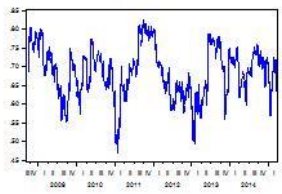

Şekil 9: 3. Dönemde Mali Alt Sektör Endeks Getirileri Arasındaki Koşullu Korelasyonlar

2008 Küresel Krizi’nin etkilerinin hissedilmeye başlanması ile birlikte ekonomide yaşanan küçülme, analiz döneminin ilk yarısında mali alt sektör endeks getirileri arasındaki oynaklık ilişkilerinde sık ve kısa süreli değişimlere neden olmuştur. Diğer yandan sınai ve hizmetler alt sektör endeks getirileri arasındaki oynaklık ilişkisinin değişimine neden olan olaylardan farklı olarak, mali sektörde yaşanan değişimlerin temel kaynağı Merkez Bankası faiz politikasındaki değişimler ve Avrupa Borç Krizi’nin etkileri olmuştur.

\section{SONUÇ}

Farklı türde gerçekleşen krizlere bağlı olarak BİST alt sektör endeks getirilerinin kendi sektör grupları içinde değişen oynaklık ilişkilerinin analiz edildiği çalışmada, alt sektör endeks getirileri arasında öncelikle sabit koşullu korelasyon testi ardından ise DCC-GARCH $(1,1)$ analizi uygulanmıştır. Sabit koşullu korelasyon testinden elde edilen sonuçlar, krizlerin ardından birçok alt sektör endeks getirisi arasındaki koşullu korelasyon yapısının değiştiğini, 2008 Küresel Krizi’nin ise koşullu korelasyon yapıları üzerinde daha fazla etkili olduğunu ortaya koymuştur.

Dinamik koşullu korelasyon analizi sonuçları ise belirlenen analiz dönemleri içinde hangi tür şok ve olayların alt sektör endeks getirileri arasındaki oynaklık ilişkilerini etkilediğini göstermiştir. 1. dönemde tüm sektörler kapsamında oynaklık ilişkilerinde genel olarak Asya ve Rusya krizi ile 1999 yılında yaşanan depremlerin değişime neden olduğu saptanmıştır. 2001 
Finansal Krizi'nden sonra ise birçok oynaklık ilişkisindeki değişimin kaynağ 2003 Körfez Savaşı olmuştur. Bununla birlikte söz konusu dönemde sınai sektör kapsamında 2002 genel seçimi ile küresel krizin başlamasına neden olan Amerika kaynaklı ekonomik gelişmelerin oynaklık yayılımlarını değiştirdiği, mali sektör kapsamında da yabancı sermaye yatırımlarındaki artışın yayımlar üzerinde etkili olduğu görülmüştür. 2008 Küresel Krizi’nden sonra oynaklık ilişkilerinde genel olarak Gezi Parkı olayları, 17-25 Aralık operasyonları ile Merkez Bankası faiz politikaları etkili olmuştur. Bu sonuçlar politik ve toplumsal olayların, sınai ve hizmetler alt sektör endeks getirileri arasındaki oynaklık ilişkileri üzerinde etkili olduğunu göstermiştir. Diğer yandan Merkez Bankası faiz politikalarının sınai ve mali alt sektör endeks getirileri arasındaki oynaklık ilişkileri üzerinde etkili olduğu belirlenmiştir. Ayrıca hizmetler alt sektör endeks getirileri arasındaki oynaklık ilişkileri, sektöre özgü olarak domuz gribi salgınından, mali sektör ise Avrupa Borç Krizi’nden etkilenmiştir.

Dinamik koşullu korelasyon analizi sonuçlarına göre; 2001 Finansal Krizi nedeniyle özellikle hizmetler alt sektör endeks getirileri, 2008 Küresel Krizi nedeniyle ise sınai ve mali alt sektör endeks getirileri arasındaki korelasyonlarda sık ve kısa süreli değişimler yaşanmış, diğer bir ifadeyle oynaklık ilişkileri farklılaşmıştır. Diğer yandan 2001 Finansal Krizi ardından tüm alt sektörler politik şoklardan etkilenmiş, özellikle mali alt sektörler arasındaki oynaklık ilişkileri de ekonomik şoklardan diğerlerine göre daha fazla etkilenmiştir. 2008 Küresel Krizi’nin ardından ise ekonomik şoklar sınai ve mali, toplumsal ve politik olaylar ise sınai ve hizmetler alt sektör getirileri arasındaki oynaklık ilişkilerinde daha fazla etkili olmuştur. Dinamik koşullu korelasyon analizi ile elde edilen bilgiler doğrultusunda çeşitlendirme yoluyla portföy riskini azaltmak isteyen yatırımcılara; sıklıkla değişen korelasyonlar nedeniyle 2001 Finansal Krizi ile benzer türde bir kriz yaşanması durumunda hizmetler alt sektör endekslerinde, 2008 Küresel Krizi ile benzer türde bir kriz yaşanması durumunda ise sınai ve mali alt sektör endekslerinde yer alan hisse senetlerini portföylerine dahil etmemeleri önerilebilir. Bununla birlikte sinai alt sektör endekslerinde yer alan hisse senetlerine yatırım yapmak isteyen yatırımcıların krizler dışında politik, toplumsal ve ekonomik olayları, mali alt sektör endekslerinde yer alan hisse senetlerine yatırım yapmak isteyen yatırımcıların özellikle ekonomik olayları takip etmeleri gerekmektedir. Hizmetler alt sektör endekslerinde yer alan hisse senetlerine yatırım yapmak isteyen yatırımcıların ise politik ve toplumsal olayların yanı sıra sektöre özgü olayları da izlemeleri gerekmektedir. 


\section{KAYNAKÇA}

Caporin, M. (2013). Equity and CDS sector indices: Dynamic models and risk hedging. The North American Journal of Economics and Finance, 25, 261-275. https://doi.org/10.1016/j.najef.2012.06.004

Chang, C., McAleer, M., \& Tansuchat, R. (2013). Conditional correlations and volatility spillovers between crude oil and stock index returns. The North American Journal of Economics and Finance, 25, 116-138. https://doi.org/10.1016/j.najef.2012.06.002

Chiang, T. C., Jeon, B. N., \& Li, H. (2007). Dynamic correlation analysis of financial contagion: Evidence from Asian markets. Journal of International Money and Finance, 26(7), 1206-1228. https://doi.org/10.1016/j.jimonfin.2007.06.005

Dimitriou, D., Kenourgios, D., \& Simos, T. (2013). Global financial crisis and emerging stock market contagion: A multivariate FIAPARCH-DCC approach. International Review of Financial Analysis, 30, 46-56. https://doi.org/10.1016/j.irfa.2013.05.008

Durai, S. R. S., \& Bhaduri, S. N. (2011). Correlation dynamics in equity markets: evidence from India. Research in International Business and Finance, 25(1), 64-74. https://doi.org/10.1016/j.ribaf.2010.07.002

Engle, R. F. (2002). Dynamic conditional correlation. Journal of Business and Economic, 20(3), 339-350. https://doi.org/10.1198/073500102288618487

Engle, R. F., \& Sheppard, K. (2001). Theoretical and empirical properties of dynamic conditional correlation $M V G A R C H$. NBER Working Paper Series No: 8554, University of California. http://www.nber.org/papers/w8554

Guesmi, K., Kaabia, O., \& Kaz1, I. (2013). Does shift contagion exist between OECD stock markets during the financial crisis?. The Journal of Applied Business Research, 29(2), 469-484. https://doi.org/10.19030/jabr.v29i2.7651

Hinojales, M., \& Park, C. (2011). Stock market integration: Emerging East Asian's experience. The dynamics of Asian financial integration. (Ed: M. B. Devereux, P. R. Lane, C. Park, \& S. Wei). Oxon: Routledge, 172203. https://www.adb.org/publications/dynamics-asian-financial-integration-facts-and-analytics

Horng, W., \& Chyan, J. (2009). A DCC analysis of two stock market returns volatility with an oil price factor: An evidence study of Singapore and Thailand's stock markets. Journal of Convergence Information Technology, 4(1), 63-69. http://www.globalcis.org/jcit/ppl/jcit040110.pdf

Hwang, E., Min, H., Kim, B., \& Kim, H. (2013). Determinants of stock market comovements among US and emerging economies during the US financial crisis. Economic Modelling, 35, 338-348. https://doi.org/10.1016/j.econmod.2013.07.021

Kearney, C., \& Poti, V. (2006). Correlation dynamics in European equity markets. Research in International Business and Finance, 20(3), 305-321. https://doi.org/10.1016/j.ribaf.2005.05.006

Lien, D., \& Yang, L. (2009). Intraday return and volatility spill-over across international copper futures markets. International Journal of Managerial https://doi.org/10.1108/17439130910932378

Min, H., \& Hwang, Y. (2012). Dynamic correlation analysis of US financial crisis and contagion: evidence from four OECD countries. Applied Financial Economics, 22(24), 2063-2074. https://doi.org/10.1080/09603107.2012.698161

Naoui, K., Khemiri, S., \& Liouane, N. (2010). Crises and financial contagion: The Subprime Crisis. Journal of Business Studies Quarterly, 2(1), 15-28. http://jbsq.org/wp-content/uploads/2010/12/JBSQ_5B.pdf

Sadorsky, P. (2012). Correlations and volatility spillovers between oil prices and the stock prices of clean energy and technology companies. Energy Economics, 34(1), 248-255. https://doi.org/10.1016/j.eneco.2011.03.006

Savva, C. S., Osborn, D. R., \& Gill, L. (2009). Spillovers and correlations between US and major European stock markets: the role of the euro. Applied Financial Economics, 19(19), 1595-1604. https://doi.org/10.1080/09603100802599563

Syllignakis, M. N., \& Kouretas, G. P. (2011). Dynamic correlation analysis of financial contagion: Evidence from the Central and Eastern European markets. International Review of Economics and Finance, 20(4), 717 732. https://doi.org/10.1016/j.iref.2011.01.006

Thao, T. P., Daly, K., \& Ellis, C. (2013). Transmission of the Global Financial Crisis to the East Asian Equity Markets. International Journal of Economics and Finance, 5(5), 171-183. https://doi.org/10.5539/ijef.v5n5p171

Wang, P., \& Moore, T. (2012). The integration of the credit default swap markets during theUS subprime crisis: Dynamic correlation analysis. Journal of International Financial Markets, Institutions \& Money, 22(1), 1-15. https://doi.org/10.1016/j.intfin.2011.07.001

Xiao, L., \& Dhesi, G. (2010). Volatility spillover and time-varying conditional correlation between the European and US stock markets. Global Economy and Finance Journal, 3(2), 148-164. http://www.gefjpapers.com/static/documents/September/2010/11.\%20Xiiaoling-FINAL.pdf 
Yiu, M. S., Ho, W. A., \& Choi, D. F. (2010). Dynamic correlation analysis of financial contagion in Asian markets in global financial turmoil. Applied Financial Economics, 20(4), 345-354. https://doi.org/10.1080/09603100903494946

Yilmaz, M. K., Sensoy, A., Oztürk, K., \& Hacihasanoglu, E. (2015). Cross-sectoral interactions in Islamic equity markets. Pacific-Basin Finance Journal, 32, 1-20. https://doi.org/10.1016/j.pacfin.2014.12.008

Ek-1: Alt Sektör Endeks Getirileri Ng-Perron Birim Kök Testi Sonuçları

Tablo 1. Ng-Peron Birim Kök Testi Sonuçları

\begin{tabular}{|c|c|c|c|c|c|c|c|c|}
\hline & \multicolumn{4}{|c|}{ Sabit } & \multicolumn{4}{|c|}{ Sabit ve Trend } \\
\hline & MZa & MZt & MSB & MPT & MZa & MZt & MSB & MPT \\
\hline XGIDA $_{1}$ & $-394.4 *$ & $-14.04 *$ & $0.036^{*}$ & $0.063^{*}$ & $-491.1 *$ & $-15.66^{*}$ & $0.032 *$ & $0.201 *$ \\
\hline $\mathrm{XGIDA}_{2}$ & $-22.67 *$ & $-3.357 *$ & $0.148 *$ & $1.114 *$ & $-78.83^{*}$ & $-6.236^{*}$ & $0.079 *$ & $1.335^{*}$ \\
\hline $\mathrm{XGIDA}_{3}$ & $-477.4 *$ & $-15.45^{*}$ & $0.032 *$ & $0.051 *$ & $-522.8 *$ & $-16.16^{*}$ & $0.031 *$ & $0.178 *$ \\
\hline XKAGT $_{1}$ & $-184.8 *$ & $-9.612 *$ & $0.052 *$ & $0.134 *$ & $-358.3 *$ & $-13.37 *$ & $0.037^{*}$ & $0.279 *$ \\
\hline XKAGT $_{2}$ & $-20.12 *$ & $-3.156^{*}$ & $0.157 *$ & $1.277 *$ & $-69.91 *$ & $-5.878^{*}$ & $0.084^{*}$ & $1.455^{*}$ \\
\hline $\mathrm{XKAGT}_{3}$ & $-417.0 *$ & $-14.44 *$ & $0.035^{*}$ & $0.060 *$ & $-627.2 *$ & $-17.69 *$ & $0.028^{*}$ & $0.167 *$ \\
\hline $\mathbf{X K M Y A ~}_{1}$ & $-419.3^{*}$ & $-14.47 *$ & $0.035^{*}$ & $0.064 *$ & $-496.3^{*}$ & $-15.74 *$ & $0.032 *$ & $0.212 *$ \\
\hline $\mathbf{X K M Y A}_{2}$ & $-14.02 *$ & $-2.616^{*}$ & $0.187 * *$ & $1.873^{* * *}$ & $-52.64 *$ & $-5.105 *$ & $0.097 *$ & $1.857 *$ \\
\hline $\mathbf{X K M Y A}_{3}$ & $-226.2 *$ & $-10.63 *$ & $0.047^{*}$ & $0.121 *$ & $-496.6^{*}$ & $-15.76^{*}$ & $0.032 *$ & $0.186^{*}$ \\
\hline $\mathbf{X M A N A}_{1}$ & $-253.2 *$ & $-11.25^{*}$ & $0.044^{*}$ & $0.097 *$ & $-423.6^{*}$ & $-14.54^{*}$ & $0.034 *$ & $0.241 *$ \\
\hline $\mathrm{XMANA}_{2}$ & $-17.17 *$ & $-2.909 *$ & $0.169 *$ & $1.505^{*}$ & $-62.72 *$ & $-5.567 *$ & $0.089 *$ & $1.605^{*}$ \\
\hline $\mathrm{XMANA}_{3}$ & $-43.19 *$ & $-4.639 *$ & $0.107^{*}$ & $0.590 *$ & $-141.7 *$ & $-8.390 *$ & $0.059^{*}$ & $0.729 *$ \\
\hline XMESY $_{1}$ & $-391.0 *$ & $-13.98 *$ & $0.036^{*}$ & $0.066^{*}$ & $-483.5^{*}$ & $-15.54 *$ & $0.032 *$ & $0.212 *$ \\
\hline $\mathrm{XMESY}_{2}$ & $-16.49 *$ & $-2.850^{*}$ & $0.173^{*}$ & $1.569 *$ & $-59.31 *$ & $-5.413 *$ & $0.091 *$ & $1.689 *$ \\
\hline $\mathrm{XMESY}_{3}$ & $-184.1 *$ & $-9.588^{*}$ & $0.052^{*}$ & $0.142 *$ & $-434.6^{*}$ & $-14.74 *$ & $0.034^{*}$ & $0.220^{*}$ \\
\hline XTAST $_{1}$ & $-377.8 *$ & $-13.74 *$ & $0.036^{*}$ & $0.066^{*}$ & $-523.6^{*}$ & $-16.17 *$ & $0.031^{*}$ & $0.196^{*}$ \\
\hline XTAST $_{2}$ & $-11.64 * *$ & $-2.384 * *$ & $0.205^{* *}$ & $2.217 * *$ & $-42.02 *$ & $-4.547 *$ & $0.108 *$ & $2.363^{*}$ \\
\hline XTAST $_{3}$ & $-317.9 *$ & $-12.61 *$ & $0.040^{*}$ & $0.077 *$ & $-572.2 *$ & $-16.90 *$ & $0.030 *$ & $0.181 *$ \\
\hline XTEKS $_{1}$ & $-286.5^{*}$ & $-11.97 *$ & $0.042^{*}$ & $0.086^{*}$ & $-443.3^{*}$ & $-14.88 *$ & $0.034 *$ & $0.225^{*}$ \\
\hline $\mathrm{XTEKS}_{2}$ & $-12.22 * *$ & $-2.447 * *$ & $0.200 * *$ & $2.105^{* *}$ & $-45.06^{*}$ & $-4.709 *$ & $0.104 *$ & $2.221 *$ \\
\hline $\mathrm{XTEKS}_{3}$ & $-258.1 *$ & $-11.36^{*}$ & $0.044^{*}$ & $0.099 *$ & $-499.8 *$ & $-15.80 *$ & $0.032 *$ & $0.191 *$ \\
\hline XELKT $_{1}$ & $-276.1 *$ & $-11.75^{*}$ & $0.043^{*}$ & $0.089 *$ & $-384.4 *$ & $-13.86^{*}$ & $0.036^{*}$ & $0.242 *$ \\
\hline XELKT $_{2}$ & $-19.99 *$ & $-3.136^{*}$ & $0.157^{*}$ & $1.319 *$ & $-73.22 *$ & $-6.029 *$ & $0.082 *$ & $1.340^{*}$ \\
\hline $\mathrm{XELKT}_{3}$ & $-189.8 *$ & $-9.741 *$ & $0.051^{*}$ & $0.130^{*}$ & $-419.4 *$ & $-14.47 *$ & $0.034^{*}$ & $0.247 *$ \\
\hline XILTM $_{1}$ & - & - & - & - & - & - & - & - \\
\hline XILTM $_{2}$ & $-28.61 *$ & $-3.759 *$ & $0.131 *$ & $0.930^{*}$ & $-102.6^{*}$ & $-7.146^{*}$ & $0.070 *$ & $0.951 *$ \\
\hline XILTM $_{3}$ & $-523.7 *$ & $-16.17 *$ & $0.031^{*}$ & $0.058 *$ & $-604.6^{*}$ & $-17.38 *$ & $0.029 *$ & $0.155^{*}$ \\
\hline $\mathrm{XSPOR}_{1}$ & - & - & - & - & - & - & - & - \\
\hline $\mathrm{XSPOR}_{2}$ & $-280.5^{*}$ & $-11.83^{*}$ & $0.042 *$ & $0.107 *$ & $-438.3^{*}$ & $-14.80 *$ & $0.034 *$ & $0.209^{*}$ \\
\hline $\mathrm{XSPOR}_{3}$ & $-866.2 *$ & $-20.81 *$ & $0.024 *$ & $0.031 *$ & $-868.1 *$ & $-20.83 *$ & $0.024 *$ & $0.108 *$ \\
\hline $\mathrm{XTCRT}_{1}$ & $-115.1 *$ & $-7.582 *$ & $0.066^{*}$ & $0.219 *$ & $-284.3^{*}$ & $-11.91 *$ & $0.042 *$ & $0.354 *$ \\
\hline XTCRT $_{2}$ & $-11.00 * *$ & $-2.311 * *$ & $0.210 * *$ & $2.366^{* *}$ & $-42.05^{*}$ & $-4.555^{*}$ & $0.108^{*}$ & $2.331 *$ \\
\hline $\mathrm{XTCRT}_{3}$ & $-262.0^{*}$ & $-11.42 *$ & $0.044 *$ & $0.124 *$ & $-467.6^{*}$ & $-15.29 *$ & $0.033 *$ & $0.197 *$ \\
\hline $\mathrm{XTRZM}_{1}$ & $-543.0 *$ & $-16.48^{*}$ & $0.030^{*}$ & $0.045^{*}$ & $-607.2 *$ & $-17.42 *$ & $0.029 *$ & $0.151 *$ \\
\hline XTRZM $_{2}$ & $-32.23 *$ & $-4.005^{*}$ & $0.124^{*}$ & $0.790 *$ & $-110.5^{*}$ & $-7.400 *$ & $0.067^{*}$ & $0.941 *$ \\
\hline $\mathrm{XTRZM}_{3}$ & $-100.0 *$ & $-7.071 *$ & $0.071^{*}$ & $0.247 *$ & $-274.2 *$ & $-11.69 *$ & $0.043^{*}$ & $0.391 *$ \\
\hline XULAS $_{1}$ & $-530.8 *$ & $-16.26^{*}$ & $0.031 *$ & $0.072 *$ & $-514.4 *$ & $-16.01 *$ & $0.031 *$ & $0.223^{*}$ \\
\hline $\mathbf{X U L A S}_{2}$ & $-22.48 *$ & $-3.327 *$ & $0.148^{*}$ & $1.178^{*}$ & $-82.43^{*}$ & $-6.400 *$ & $0.078^{*}$ & $1.188^{*}$ \\
\hline $\mathbf{X U L A S}_{\mathbf{3}}$ & $-143.8 *$ & $-8.476^{*}$ & $0.059 *$ & $0.174 *$ & $-367.7 *$ & $-13.54 *$ & $0.037^{*}$ & $0.279 *$ \\
\hline $\mathrm{XBANK}_{1}$ & $-296.7 *$ & $-12.18 *$ & $0.041^{*}$ & $0.083^{*}$ & $-413.9 *$ & $-14.37 *$ & $0.035^{*}$ & $0.256^{*}$ \\
\hline $\mathrm{XBANK}_{2}$ & $-16.56^{*}$ & $-2.859 *$ & $0.173^{*}$ & $1.553 *$ & $-60.55^{*}$ & $-5.466^{*}$ & $0.090^{*}$ & $1.674 *$ \\
\hline $\mathrm{XBANK}_{3}$ & $-183.3 *$ & $-9.573 *$ & $0.052 *$ & $0.134 *$ & $-413.9 *$ & $-14.37 *$ & $0.035^{*}$ & $0.256^{*}$ \\
\hline XFINK $_{1}$ & $-362.6^{*}$ & $-13.46^{*}$ & $0.037^{*}$ & $0.071 *$ & $-542.4 *$ & $-16.47 *$ & $0.030^{*}$ & $0.170^{*}$ \\
\hline XFINK $_{2}$ & $-21.14 *$ & $-3.236^{*}$ & $0.153^{*}$ & $1.213 *$ & $-75.25 *$ & $-6.099 *$ & $0.081^{*}$ & $1.360 *$ \\
\hline XFINK $_{3}$ & $-245.7 *$ & $-11.08 *$ & $0.045^{*}$ & $0.100 *$ & $-502.0 *$ & $-15.83^{*}$ & $0.032 *$ & $0.201 *$ \\
\hline XGMYO $_{1}$ & - & - & - & - & - & - & - & - \\
\hline $\mathrm{XGMYO}_{2}$ & $-14.84 *$ & $-2.702 *$ & $0.182 * *$ & $1.735^{*}$ & $-54.58 *$ & $-5.188^{*}$ & $0.095^{*}$ & $1.846^{*}$ \\
\hline $\mathrm{XGMYO}_{3}$ & $-118.1 *$ & $-7.681^{*}$ & $0.065^{*}$ & $0.213 *$ & $-316.5^{*}$ & $-12.57 *$ & $0.040^{*}$ & $0.323^{*}$ \\
\hline XHOLD $_{1}$ & $-340.6^{*}$ & $-13.05^{*}$ & $0.038 *$ & $0.074 *$ & $-473.4 *$ & $-15.37 *$ & $0.032 *$ & $0.220^{*}$ \\
\hline $\mathrm{XHOLD}_{2}$ & $-16.42 *$ & $-2.845^{*}$ & $0.173^{*}$ & $1.570^{*}$ & $-59.68 *$ & $-5.428 *$ & $0.091^{*}$ & $1.691 *$ \\
\hline $\mathrm{XHOLD}_{3}$ & $-321.1 *$ & $-12.67 *$ & $0.039 *$ & $0.079 *$ & $-590.5^{*}$ & $-17.18 *$ & $0.029 *$ & $0.160 *$ \\
\hline XSGRT $_{1}$ & $-298.4 *$ & $-12.21 *$ & $0.041^{*}$ & $0.084 *$ & $-421.0 *$ & $-14.49 *$ & $0.034 *$ & $0.246^{*}$ \\
\hline $\mathrm{XSGRT}_{2}$ & $-16.53 *$ & $-2.854 *$ & $0.173^{*}$ & $1.560 *$ & $-60.73 *$ & $-5.476^{*}$ & $0.090^{*}$ & $1.663^{*}$ \\
\hline $\mathrm{XSGRT}_{3}$ & $-369.9 *$ & $-13.60 *$ & $0.037 *$ & $0.067 *$ & $-598.7 *$ & $-17.29 *$ & $0.029 *$ & $0.174 *$ \\
\hline
\end{tabular}

1, 2, 3 ilgili dönem için hesaplanan test istatistiklerini göstermektedir. $* \% 1 * * \% 5 * * * \% 10$ anlam düzeyi 
Ek-2: Alt Sektör Endeks Getirileri Sabit Koşullu Korelasyon Testi Sonuçları

Tablo 2. Sınai Alt Sektör Endeks Getirileri İçin Sabit Koşullu Korelasyon Testi Sonuçları

\begin{tabular}{|c|c|c|c|c|c|}
\hline & 1.Dönem & & 2.Dönem & & 3.Dönem \\
\hline XGIDA_XKAGT & 4.51 & XGIDA_XKAGT & 7.94 & XGIDA_XKAGT & 5.016 \\
\hline XGIDA_XKMYA & 10.01 & XGIDA_XKMYA & $10.77 * * *$ & XGIDA_XKMYA & 6.128 \\
\hline XGIDA_XMANA & 7.74 & XGIDA_XMANA & 8.620 & XGIDA_XMANA & $21.30 * *$ \\
\hline XGIDA_XMESY & 10.16 & XGIDA_XMESY & 9.060 & XGIDA_XMESY & 9.314 \\
\hline XGIDA_XTAST & 8.44 & XGIDA_XTAST & 9.528 & XGIDA_XTAST & 10.34 \\
\hline XGIDA_XTEKS & $13.51 * *$ & XGIDA_XTEKS & $11.60 * * *$ & XGIDA_XTEKS & $11.51 * *$ \\
\hline XKAGT_XKMYA & $12.65^{* *}$ & XKAGT_XKMYA & $14.25 * *$ & XKAGT_XKMYA & 8.756 \\
\hline XKAGT_XMANA & $25.89 *$ & XKAGT_XMANA & $17.11 *$ & XKAGT_XMANA & 9.369 \\
\hline XKAGT_XMESY & $21.69 *$ & XKAGT_XMESY & $17.94 *$ & XKAGT_XMESY & 7.835 \\
\hline XKAGT_XTAST & $19.18^{*}$ & XKAGT_XTAST & 9.156 & XKAGT_XTAST & $21.36^{*}$ \\
\hline XKAGT_XTEKS & $14.83^{* *}$ & XKAGT_XTEKS & $18.01 *$ & XKAGT_XTEKS & $19.75^{*}$ \\
\hline XKMYA XMANA & $37.46^{*}$ & XKMYA XMANA & $38.38 *$ & XKMYA XMANA & $19.51 *$ \\
\hline XKMYA_XMESY & $65.51 *$ & XKMYA_XMESY & $25.624 *$ & XKMYA_XMESY & $11.44 * * *$ \\
\hline XKMYA_XTAST & $64.12 *$ & XKMYA_XTAST & $17.48 *$ & XKMYA_XTAST & 8.778 \\
\hline XKMYA_XTEKS & $35.30 *$ & XKMYA_XTEKS & $25.84 *$ & XKMYA_XTEKS & $33.89 *$ \\
\hline XMANA_XMESY & $11.73 * * *$ & XMANA_XMESY & $43.24 *$ & XMANA_XMESY & $13.53 * *$ \\
\hline XMANA_XTAST & $39.30 *$ & XMANA_XTAST & $13.56 * *$ & XMANA_XTAST & $21.00 *$ \\
\hline XMANA_XTEKS & $38.35^{*}$ & XMANA_XTEKS & $18.25^{*}$ & XMANA_XTEKS & $11.88 * * *$ \\
\hline XMESY_XTAST & $15.15^{* *}$ & XMESY_XTAST & $24.21 *$ & XMESY_XTAST & $17.09 *$ \\
\hline XMESY_XTEKS & $47.16^{*}$ & XMESY_XTEKS & $21.00 * * *$ & XMESY_XTEKS & $24.51 *$ \\
\hline XTAST_XTEKS & $114.3^{*}$ & XTAST_XTEKS & $12.26 * * *$ & XTAST_XTEKS & $35.23^{*}$ \\
\hline
\end{tabular}

*\%1 **\%5 ***\%10 anlam düzeyi

Tablo 3. Hizmetler Alt Sektör Endeks Getirileri İçin Sabit Koşullu Korelasyon Testi Sonuçları

\begin{tabular}{lclclc}
\hline & 1.Dönem & & 2.Dönem & & 3.Dönem \\
\hline XTCRT_XTRZM & $31.830^{*}$ & XELKT_XILTM & 10.238 & XELKT_XILTM & 8.402 \\
XTCRT_XULAS & 7.359 & XELKT_XTCRT & $21.589^{*}$ & XELKT_XSPOR & $27.215^{*}$ \\
XTRZM_XULAS & $20.861^{*}$ & XELKT_XTRZM & 9.073 & XELKT_XTCRT & $15.930^{* *}$ \\
& & XELKT_XULAS & $21.268^{*}$ & XELKT_XTRZM & $15.458^{* *}$ \\
& & XILTM_XTCRT & $11.723^{* * *}$ & XELKT_XULAS & $16.780^{* *}$ \\
& XILTM_XTRZM & $26.299^{*}$ & XILTM_XSPOR & $13.588^{* *}$ \\
& XILTM_XULAS & $11.859^{* * *}$ & XILTM_XTCRT & $20.359^{*}$ \\
& XTCRT_XTRZM & 8.939 & XILTM_XTRZM & $18.910^{*}$ \\
& XTCRT_XULAS & $23.758^{*}$ & XILTM_XULAS & $28.083^{*}$ \\
& XTRZM_XULAS & $18.464^{*}$ & XSPOR_XTCRT & 5.566 \\
& & & XSPOR_XTRZM & $16.440^{* *}$ \\
& & & XSPOR_XULAS & $16.167^{* *}$ \\
& & & XTCRT_XTRZM & $11.801^{* * *}$ \\
& & & XTCRT_XULAS & $24.616^{*}$ \\
& & & & & \\
& & & & & \\
& & & & &
\end{tabular}

$* \% 1 * * \% 5 * * * \% 10$ anlam düzeyi

Tablo 4. Mali Alt Sektör Endeks Getirileri İçin Sabit Koşullu Korelasyon Testi Sonuçları

\begin{tabular}{lclclc}
\hline & 1.Dönem & & 2.Dönem & & 3.Dönem \\
\hline XBANK_XFINK & $66.340^{*}$ & XBANK_XFINK & $20.821^{*}$ & XBANK_XFINK & $25.595^{*}$ \\
XBANK_XHOLD & $33.826^{*}$ & XBANK_XGMYO & $20.269^{*}$ & XBANK_XGMYO & $8.591^{* * *}$ \\
XBANK_XSGRT & $46.138^{*}$ & XBANK_XHOLD & $13.528^{* *}$ & XBANK_XHOLD & 1.753 \\
XFINK_XHOLD & $44.938^{*}$ & XBANK_XSGRT & $15.329^{* *}$ & XBANK_XSGRT & $28.808^{*}$ \\
XFINK_XSGRT & $44.426^{*}$ & XFINK_XGMYO & $16.649^{* *}$ & XFINK_XGMYO & $15.829^{* *}$ \\
XHOLD_XSGRT & $37.977^{*}$ & XFINK_XHOLD & $20.731^{*}$ & XFINK_XHOLD & 7.523 \\
& & XFINK_XSGRT & $23.857^{*}$ & XFINK_XSGRT & $26.265^{*}$ \\
& & XGMYO_XHOLD & $23.456^{*}$ & XGMYO_XHOLD & $11.935^{* * *}$ \\
& & XGMYO_XSGRT & $17.312^{*}$ & XGMYO_XSGRT & $33.917^{*}$ \\
& & XHOLD_XSGRT & 8.321 & XHOLD_XSGRT & $24.944^{*}$ \\
\hline
\end{tabular}


Ek-3: Alt Sektör Endeks Getirileri DCC-GARCH(1,1) Modeli Sonuçları

Tablo 5. Sınai Alt Sektör Endeks Getirileri İçin DCC-GARCH(1,1) Modeli Sonuçları

\begin{tabular}{|c|c|c|c|c|c|c|c|c|}
\hline & \multicolumn{2}{|c|}{ 1. Dönem } & \multicolumn{4}{|c|}{ 2. Dönem } & \multicolumn{2}{|c|}{ 3. Dönem } \\
\hline & $\Theta_{1}$ & $\Theta_{2}$ & & $\Theta_{1}$ & $\Theta_{2}$ & & $\Theta_{1}$ & $\Theta_{2}$ \\
\hline XGIDA_XTEKS & $0.100^{*}$ & $0.760 *$ & XGIDA_XKMYA & $0.018^{*}$ & $0.962 *$ & XGIDA_XMANA & 0.020 & $0.835^{*}$ \\
\hline XKAGT_XKMYA & $0.030 *$ & $0.949 *$ & XGIDA_XTEKS & $0.016^{*}$ & $0.960 *$ & XGIDA_XTEKS & $0.036^{* *}$ & $0.867 *$ \\
\hline XKAGT_XMANA & $0.119 *$ & $0.751^{*}$ & XKAGT_XKMYA & $0.023 *$ & $0.959 *$ & XKAGT__XTAST & $0.065 *$ & $0.900 *$ \\
\hline XKAGT_XMESY & $0.055^{*}$ & $0.890 *$ & XKAGT_XMANA & $0.032 *$ & $0.941 *$ & XKAGT_XTEKS & $0.058 *$ & $0.882 *$ \\
\hline XKAGT_XTAST & $0.074 *$ & $0.894 *$ & XKAGT_XMESY & -0.044 & 1.152 & XKMYA_XMANA & $0.044 *$ & $0.875^{*}$ \\
\hline XKAGT_XTEKS & $0.084 *$ & $0.797 *$ & XKAGT_XTEKS & $0.042 *$ & $0.918 *$ & XKMYA_XMESY & $0.059 *$ & $0.842 *$ \\
\hline XKMYA_XMANA & $0.075^{*}$ & $0.859 *$ & XKMYA_XMANA & $0.042 *$ & $0.940 *$ & XKMYA_XTEKS & $0.016 * * *$ & $0.943 *$ \\
\hline XKMYA_XMESY & $0.120 *$ & $0.772 *$ & XKMYA_XMESY & $0.036^{*}$ & $0.948 *$ & XMANA_XMESY & $0.061 *$ & $0.893 *$ \\
\hline XKMYA_XTAST & $0.066^{*}$ & $0.907 *$ & XKMYA_XTAST & $0.035^{*}$ & $0.936^{*}$ & XMANA_XTAST & $0.058 *$ & $0.856^{*}$ \\
\hline XKMYA_XTEKS & $0.096^{*}$ & $0.791 *$ & XKMYA_XTEKS & $0.016^{*}$ & $0.973 *$ & XMANA_XTEKS & $0.058 * *$ & $0.842 *$ \\
\hline XMANA_XMESY & $0.072 *$ & $0.837 *$ & XMANA_XMESY & $0.034 *$ & $0.953 *$ & XMESY_XTAST & $0.069 *$ & $0.867 *$ \\
\hline XMANA_XTAST & $0.109 *$ & $0.792 *$ & XMANA_XTAST & $0.036^{*}$ & $0.940 *$ & XMESY_XTEKS & $0.046^{*}$ & $0.889 *$ \\
\hline XMANA_XTEKS & $0.109 *$ & $0.761 *$ & XMANA_XTEKS & $0.027 *$ & $0.955^{*}$ & XTAST_XTEKS & $0.115^{*}$ & $0.784 *$ \\
\hline XMESY_XTAST & $0.101 *$ & $0.833^{*}$ & XMESY_XTAST & $0.042 *$ & $0.912 *$ & & & \\
\hline XMESY_XTEKS & $0.075^{*}$ & $0.860^{*}$ & XMESY_XTEKS & $0.017 *$ & $0.963 *$ & & & \\
\hline XTAST_XTEKS & $0.132 *$ & $0.793^{*}$ & XTAST_XTEKS & $0.048 *$ & $0.900 *$ & & & \\
\hline
\end{tabular}

$* \% 1 * * \% 5 * * * \% 10$ anlam düzeyi. $\Theta_{1}$ ARCH parametresini, $\Theta_{1}$ GARCH parametresini göstermektedir.

Tablo 6. Hizmet Alt Sektör Endeks Getirileri İçin DCC-GARCH(1,1) Modeli Sonuçları

\begin{tabular}{|c|c|c|c|c|c|c|c|c|}
\hline & \multicolumn{2}{|c|}{ 1. Dönem } & \multicolumn{4}{|c|}{ 2. Dönem } & \multicolumn{2}{|c|}{ 3. Dönem } \\
\hline & $\Theta_{1}$ & $\Theta_{2}$ & & $\Theta_{1}$ & $\Theta_{2}$ & & $\Theta_{1}$ & $\Theta_{2}$ \\
\hline XTCRT_XTRZM & $0.048 *$ & $0.906^{*}$ & XELKT_XTCRT & $0.006^{* * *}$ & $0.992 *$ & XELKT_XSPOR & $0.026 * *$ & $0.920 *$ \\
\hline XTRZM_XULAS & $0.092 *$ & $0.749^{*}$ & XELKT_XULAS & $0.012 * *$ & $0.977 *$ & XELKT_XTCRT & $0.014 *$ & $0.971 *$ \\
\hline & & & XILTM_XTCRT & $0.046^{*}$ & $0.819^{*}$ & XELKT_XTRZM & $0.046^{* *}$ & $0.901 *$ \\
\hline & & & XILTM_XTRZM & $0.076^{*}$ & $0.722 *$ & XELKT_XULAS & $0.020 * *$ & $0.961 *$ \\
\hline & & & XILTM_XULAS & $0.018 * *$ & $0.923 *$ & XILTM_XSPOR & 0.013 & $0.963 *$ \\
\hline & & & XTCRT_XULAS & $0.030^{*}$ & $0.932 *$ & XILTM_XTCRT & $0.036 *$ & $0.920 *$ \\
\hline & & & XTRZM_XULAS & $0.042 *$ & $0.810 *$ & XILTM_XTRZM & $0.048 *$ & $0.858 *$ \\
\hline & & & & & & XILTM_XULAS & $0.019 *$ & $0.972 *$ \\
\hline & & & & & & XSPOR_XTRZM & 0.031 ** & $0.854 *$ \\
\hline & & & & & & XSPOR_XULAS & $0.034 * *$ & $0.818 *$ \\
\hline & & & & & & XTCRT_XTRZM & $0.062 *$ & $0.821 *$ \\
\hline & & & & & & XTCRT_XULAS & $0.052 *$ & $0.784 *$ \\
\hline & & & & & & XTRZM_XULAS & $0.061 *$ & $0.873 *$ \\
\hline
\end{tabular}

$* \% 1$ **\%5 ***\%10 anlam düzeyi. $\Theta_{1} \mathrm{ARCH}$ parametresini, $\Theta_{1} \mathrm{GARCH}$ parametresini göstermektedir.

Tablo 7. Mali Alt Sektör Endeks Getirileri İçin DCC-GARCH(1,1) Modeli Sonuçları

\begin{tabular}{lcclcccccc}
\hline & \multicolumn{3}{c}{ 1. Dönem } & \multicolumn{3}{c}{ 2. Dönem } & \multicolumn{3}{c}{ 3. Dönem } \\
\hline & $\Theta_{1}$ & $\Theta_{2}$ & & $\Theta_{1}$ & $\Theta_{2}$ & & $\Theta_{1}$ & $\Theta_{2}$ \\
\hline XBANK_XFINK & $0.045^{*}$ & $0.918^{*}$ & XBANK_XFINK & $0.039^{*}$ & $0.879^{*}$ & XBANK_XFINK & $0.065^{*}$ & $0.823^{*}$ \\
XBANK_XHOLD & $0.049^{*}$ & $0.927^{*}$ & XBANK_XGMYO & $0.034^{*}$ & $0.936^{*}$ & XBANK_XGMYO & $0.024^{*}$ & $0.961^{*}$ \\
XBANK_XSGRT & $0.042^{* *}$ & $0.921^{*}$ & XBANK_XHOLD & $0.041^{*}$ & $0.924^{*}$ & XBANK_XSGRT & $0.053^{*}$ & $0.882^{*}$ \\
XFINK_XHOLD & $0.053^{*}$ & $0.899^{*}$ & XBANK_XSGRT & $0.032^{*}$ & $0.929^{*}$ & XFINK_XGMYO & $0.074^{*}$ & $0.809^{*}$ \\
XFINK_XSGRT & $0.029^{* *}$ & $0.941^{*}$ & XFINK_XGMYO & $0.060^{*}$ & $0.773^{*}$ & XFINK_XSGRT & $0.070^{*}$ & $0.878^{*}$ \\
XHOLD_XSGRT & $0.045^{*}$ & $0.940^{*}$ & XFINK_XHOLD & $0.040^{*}$ & $0.838^{*}$ & XGMYO_XHOLD & $0.025^{*}$ & $0.956^{*}$ \\
& & & XFINK_XSGRT & $0.052^{*}$ & $0.790^{*}$ & XGMYO_XSGRT & $0.048^{*}$ & $0.880^{*}$ \\
& & & XGMYO_XHOLD & $0.033^{*}$ & $0.940^{*}$ & XHOLD_XSGRT & $0.032^{*}$ & $0.916^{*}$ \\
& & & XGMYO_XSGRT & $0.029^{*}$ & $0.949^{*}$ & & & & \\
\hline
\end{tabular}

*\%1 **\%5 ***\%10 anlam düzeyi. $\Theta_{1} \mathrm{ARCH}$ parametresini, $\Theta_{1} \mathrm{GARCH}$ parametresini göstermektedir. 